\title{
La Constitución alemana de Weimar (1919) ¿una utopía en medio de la crisis? Un análisis histórico a sus aspectos interventores, modernizadores y derechos sociales*
}

\author{
The German Constitution of Weimar (1919). A Utopia \\ in the Midst of the Crisis? A Historical Analysis of Its \\ Interventative, Modernizing and Social Rights Aspects
}

\author{
Juan David Restrepo Zapata**
}

\begin{abstract}
RESUMEN
El presente artículo estudia, desde una mirada interdisciplinar, algunos postulados de la Constitución alemana de 1919, en sus aspectos interventores, modernizadores y de derechos sociales. Consecuentemente, este texto analiza en profundidad el entramado constitucional promulgado en la ciudad de Weimar, tras el fin de la Primera Guerra Mundial, que fue guiado, en mayor medida, por postulados socialdemócratas que veían en la revolución comunista un peligro latente que debía ser frenado. Algunos de los avances en materia interventora de la Constitución, permitían la vinculación directa del Estado en la regulación y control de aspectos económicos, políticos y sociales, entre otros. Frente a la modernización, se reformaron aspectos básicos de la tradición en cuanto a las instituciones, el poder, las relaciones y acciones políticas y democráticas, así como los vínculos Igle-
\end{abstract}

* Este artículo es resultado parcial del Proyecto de Investigación "La República Liberal frente a la República de Weimar: un análisis comparado de la Constitución alemana (1919) y las reformas a la Constitución colombiana (1936)", proyecto realizado para optar por el título de Historiador en la Universidad de Antioquia, Colombia.

* Universidad de Antioquia. Investigador e integrante del grupo de Investigación Estudios Interdisciplinares en Historia General, adscrito a la Facultad de Ciencias Sociales y Humanas de la Universidad de Antioquia. Correo: juandrestrepozapata@gmail.com. Recibido: 2I de diciembre de 20I7. Aceptado: 8 de mayo de 2018. 
sia-Estado. Y, finalmente, respecto del campo social, se ampliaron y promulgaron algunos derechos laborales, sindicales y otros que contemplaban la seguridad social de los habitantes del país germano.

Palabras clave: Alemania - Constitución de Weimar - Estado interventor - modernización - derechos sociales.

\section{ABSTRACT}

The present article studies from an interdisciplinary perspective some postulates of the German Constitution of 1919 in its intervening, modernizing and social rights aspects. Consequently, this text, analyzes in depth the constitutional framework enacted in the city of Weimar after the end of the World War One, which was guided to a greater extent by social democratic postulates that saw in the communist revolution a latent danger that had to be stopped. Some of the advances in the intervening matter of the Constitution, allowed the direct link of the State in the regulation and control of economic, political, social aspects, among others. In the face of modernization, basic aspects of the tradition were reformed in terms of institutions, power, relations and political and democratic actions, Church-State bonds. And finally, regarding the social field, some labor, union and some other rights that contemplated the social security of the inhabitants of the Germanic country were extended and enacted.

Keywords: Germany - Weimar Constitution - State Interventionism - Modernization - Social Rights. 
Juan David Restrepo Zapata

La Constitución alemana de Weimar (1919) ¿una utopía en medio de la crisis? Un

análisis histórico a sus aspectos interventores, modernizadores y derechos sociales

\section{El Imperio ALEMÁN y loS AÑoS DE AGitación, I870-I9I9}

La Alemania imperial fue una invención que abogó por la unidad, la cohesión y el progreso de su pueblo y Estado. Los disgregados principados tuvieron su final como entidades políticas independientes en I87I, cuando, bajo la dirección de la élite aristocrática prusiana — una maquinaria estatal poderosa- rompió con los ánimos fragmentarios de los pueblos que habitaban los territorios entre el rio Rin y el Oder. La carrera imperialista estaba servida y la economía, la política y la guerra, fueron las bases para consolidar el proyecto expansionista germano (Hobsbawm, 2009, p. I24-I25). El nuevo Estado-nación se caracterizó por su modelo conservador, que mantenía muchas de las características del Antiguo Régimen — siendo el monarca la máxima cabeza del Estado-, pero dando representatividad, mediante el Parlamento, a la aristocracia y a la burguesía; de la misma manera sentaba las bases para consolidar un sector burgués poderoso, que movilizara la industria y la economía nacional. Al mismo tiempo, el país ostentó una explosión demográfica, que representó un aumento poblacional de casi el 63\% entre I87I y I9I4, pasando de 4I millones a 67,7 millones en 43 años. Esto, a su vez, provocó una urbanización acelerada, donde se incrementó la mano de obra y la división social se hizo más tangible (Fulbrook, 2009, p. I9I).

Las crisis económicas de la segunda mitad del siglo xIx fueron alternadas con períodos de alto desarrollo industrial. Poco a poco, la antigua producción carbonífera, de metales y de ingeniería pesada, se transformó en un progreso científico, tecnológico y manufacturero, que visibilizó a la empresa alemana por sobre la inglesa. Una de las características diferenciadoras del antiguo modelo alemán era su forma de ver la educación del proletariado como garantía para el incremento productivo. La enseñanza básica era obligatoria y las posibilidades de formación superior, con una influencia del sector industrial, contribuyeron a la cualificación de la clase obrera germana que potenció la productividad hombre-hora, comparado con otros países industriales como Gran Bretaña o Francia (Kühnl, I99I, p. I9). Además, a diferencia del liberalismo comercial inglés, Alemania procuró construir un sistema con algunas características interventoras en sus aspectos económicos (Fulbrook, 2009, p. I93).

La sociedad alemana estaba fuertemente dividida en tres sectores: el primero, los junker, herederos de los tradicionales poderes terratenientes, cuyo eje de influencia estaba dado en el mundo rural, decadente por la rápida migración a las ciudades. Un segundo sector, ubicado en los industriales, promotores de medidas estatales - como la reducción de aranceles-, tropezaba en muchas ocasiones con los intereses terratenientes. Adicionalmente, el crecimiento de un tercer sector, el obrero, supuso un choque con las partes 
anteriormente descritas y con algunas políticas estatales, lo que fomentó la creación de agrupaciones sindicales y el apoyo a partidos en florecimiento, como el Partido Socialdemócrata o SPD. De esta manera, la balanza electoral comenzó a inclinarse hacia partidos obrero-sindicales, por el peso que ejercían las tasas de crecimiento demográfico urbano y, con él, el aumento del proletariado en las principales ciudades alemanas, por lo que no fue casualidad que partidos socialdemócratas, como el SPD, obtuvieran victorias contundentes en el Reichstag: para I9I2, fue el partido más votado de Alemania (Fulbrook, 2009, p. 194), y contaba con I,I millón de afiliados, mientras que los sindicatos registraban cifras de 2,5 millones de integrantes (Kühnl, I99I, p. 19). Es de resaltar que según la historiadora Mary Fulbrook, "las élites de la Alemania imperial no eran, por lo general, capaces de apreciar las sutiles distinciones sociológicas, y se limitaban sencillamente a temer la amenaza de la revolución desde abajo, sin examinar en profundidad los auténticos objetivos y la capacidad de acción de los distintos sectores del proletariado alemán” (Fulbrook, 2009, p. 195).

El ocaso de la Alemania de Otto von Bismark fue un caldo de cultivo para ocasionar fuertes choques entre las distintas capas de la sociedad. Muchos de los históricamente favorecidos consiguieron, mediante una "solidaridad de intereses más bien negativa, (...) aunar sus diferencias y juntarse contra la amenaza del enemigo común, que se adivinaba por debajo" (Fulbrook, 2009, p. 197). Una de estas asociaciones tomó el nombre de "alianza del centeno y el acero", que se inclinó hacia una tendencia antisocialista. Frente a estas presiones de las élites del país, el gobierno promulgó una serie de ablandamientos de las leyes que controlaban la economía, favoreciendo - de nuevoa ambos sectores antes mencionados. Las tradicionales relaciones de poder, herederas del pasado prusiano, nunca asumieron su papel frente a cuestiones fundamentales de la sociedad que se construía rápidamente en Alemania. Los vaivenes de la política interior giraban sin llegar a soluciones de fondo (Fulbrook, 2009, p. 213).

En 19I4, la Primera Guerra Mundial llegó como la noticia más esperada de Europa. Los Estados habían alistado su maquinaria bélica con mucha anticipación y los esquemas tradicionales de los choques armados dejaban pensar que la tan esperada confrontación duraría poco más de unos cuantos meses. Nunca se imaginaron que las nuevas tecnologías transformarían los ríos en sangre; mucho menos que los meses se convertirían en años.

Para mediados de 1918, el fin de la Guerra era ya inevitable; guerra de la cual el Imperio alemán había salido derrotado. La Gran Guerra acentuó las divisiones internas de la sociedad germana, y parcialmente borró a las clases medias, marcando con mayor ahínco al sector de la élite industrial, monopolístico del capital y al sector obrero empobrecido, del cual eran sub- 
sidiarios los grandes sindicatos, ahora reconocidos por el Estado. La Guerra, sin embargo, posibilitó la organización de los trabajadores, que habían sido esenciales para el mantenimiento económico del Imperio. Se les dotó de una estructura que comenzaría a marcar la vida política de Alemania y a sus bases se les incorporó la presencia de sectores históricamente excluidos, tales como las mujeres y los jóvenes (Fulbrook, 2009, p. 217).

Fue, entonces, necesaria una recomposición de la estructura de Alemania, que era presionada por la gran agitación interna del país. Muchos de los señalamientos iban dirigidos a culpar a uno u otro bando, así que para la izquierda "era evidente que el pueblo alemán había sido descarriado y engañado por los militares irresponsables y sus aliados en las altas clases sociales" (Parker, 1987, p. 243). Para octubre de I9I8, las primeras reformas tendieron a desmilitarizar la dirección del Estado -en parte para dilatar los señalamientos hacia la responsabilidad del Ejército en la pérdida de la guerra-, por lo que un gobierno civil tomó el control parcial. Desde allí se dieron pasos hacia unas reformas al sistema electoral, al Parlamento y al sistema monárquico, que estaría supeditado a una constitución, aspectos que Guillermo III nunca aceptó y su camino único fue la abdicación y exilio en Holanda, cosa que finalmente ocurrió el 9 de noviembre del mismo año (Fulbrook, 2009, p. 2I8). Un fragmento del periódico $\mathrm{ABC}$ de Madrid del Io de noviembre de 19I8, informaba que: "El Emperador y el príncipe heredero han abdicado. Ha sido derrumbada la dinastía. Es una brillante victoria del pueblo alemán. Ebert ha sido encargado de formar un nuevo gobierno, en el que tendrán cabida todas las ideas del partido social-demócrata".

Los levantamientos comenzaron a aparecer por toda Alemania. Sectores militares se rebelaron contra algunos aspectos de su estructura jerárquica y tomaron el poder de localidades. También, mediante la figura de "consejos", los obreros se amotinaron y arrebataron al Estado el control de algunas poblaciones, donde el objetivo se convirtió en democratizar y "transformar el régimen de propiedad; en una palabra, se pretendía instaurar el socialismo" (Kühnl, I99I, p. 23). Esta figura de Consejos era vista como un movimiento que "permitía la acción política desde la base" (Kühnl, I99I, p. 23). Mientras tanto, con el titular "Alemania hacia la República Socialista”, la prensa sostenía que:

"Al propio tiempo que en Berlín se sustituía el antiguo régimen por un Gobierno popular, y se constituía en la capital un Consejo de obreros y soldados, el movimiento revolucionario se extendía por toda la nación. De todas partes llegan noticias sobre la formación de Consejos de obreros y soldados.

1 ABC, Madrid, Io de noviembre de I9I8, pág. 9. 
En general, la revolución se deslizó sin alteración esencial del orden económico y sin derramamiento de sangre. En muchas ciudades fue reconocido, sin vacilación alguna, el Consejo de Obreros y Soldados por las autoridades militares, encargándose de la administración municipal"?.

Las condiciones para la revolución — de estilo marxista- estaban servidas, aunque fueron enfriadas por una serie de compromisos que, "aunque a corto plazo parecían estabilizadores, en realidad lo que hacían era encubrir, y no resolver, tensiones cuyo estallido posterior sería más poderoso" (Fulbrook, 2009, p. 220). El gobierno transicional fue asumido por el partido SPD en cabeza de Friedrich Ebert, promotor de una Asamblea Nacional Constituyente, que transformara al Estado en una república democrática y que resolviera los grandes problemas del momento, tales como la firma del armisticio, la desmovilización del Ejército, evitar la revolución y levantar la economía (Fulbrook, 2009, p. 220).

Cabe mencionar que el levantamiento de los Consejos era catalogado como comunista, es más, según el ABC de Madrid, ni siquiera el gobierno conformado por Ebert era capaz de controlar al turbado proletariado que quería "hacer realidad el Manifiesto Comunista de Carlos Marx. (...) La

2 ABC, Madrid, II de noviembre de I9I8, pág. 7. masa obrera se alista en el bando comunista”. Mientras tanto, los dirigentes socialdemócratas, "Ebert y Scheidmann gritan, invocan a la libertad, a la democracia; claman contra el terror de una minoría y contra la revolución que les amenaza"3. Una especie de prolongación de lo acaecido en el octubre ruso de I9I7 (Carr, I968, p. 203) o, por lo menos, así lo veían venir.

Fue a partir de allí que la refundación de Alemania incurrió en la aparición de alianzas que vinculaban a sectores conservadores — donde se incluyó a los militares y, por supuesto, a los industriales - con el gobierno y los sindicatos. La gran solicitud del sector castrense fue la moderación del proceso y la supresión de los consejos levantados por todo el país - intentado así eliminar el aliento comunista de las decisiones gubernamentales-, mientras que los industriales se comprometieron a endosar un reforzamiento de las garantías laborales de sus empleados, a cambio del mantenimiento de su poder económico.

Estos movimientos negociadores fragmentaban con regularidad la cohesión de partidos como el SPD, al cual le reclamaban mayor compromiso en la defensa de sus ideales, segregándose de él partidos como el Comunista de Alemania KPD, y el espartaquista. La agitación llegó a un punto de no retorno, del cual surgieron grupos de

3 ABC, Madrid, 5 de febrero de I9I9, "Apuntes para la historia de la revolución alemana”, pág. 3 . 
extrema derecha armados, denominados Freikorps, con financiamiento de los industriales y con el auspicio de los militares. En parte, estas estructuras derivaron de la desmovilización acelerada que se implementó en el Ejército - algo forzado, además, por la pérdida de la guerra-. Lo anterior brindó la sensación de presenciar la unión entre socialdemócratas y sectores conservadores para impedir la trasformación del statu quo. Un ejemplo de ello, para muchos, fue la sofocación de los intentos revolucionarios en Baviera y Múnich, de corte comunista, que fueron contenidos por el Ejército y las Freikorps.

Es de resaltar que gran parte de la socialdemocracia veía en el parlamentarismo el mecanismo para conseguir sus ideales políticos, dentro del marco del orden, la tranquilidad y la legalidad, por lo cual, atentar contra esta posibilidad de acción política — nacida del mundo burgués - era vista como dañina por ese sector. El mismo Friedrich Ebert invitaba a adoptar el sistema parlamentario, de lo contrario, "la revolución social será inevitable. Desde luego, yo no la deseo, es más, la odio como a un delito" (Von Baden, 1927, p. 600; tomado de Kühnl, 199I, p. 26). La búsqueda de la revolución no era opción, más bien su extinción era por lo que combatían en conjunto con otros sectores. De este modo, diversos movimientos políticos se oponían al radicalismo, buscando una "colaboración interclasista, de la conformidad no con la disciplina revolucionaria, sino con la disciplina que se deriva de las tareas concretas" (Weiss, 1975, p. 106 y 109; tomado de Kühnl, I99I, p. 27).

De esta manera, junto con una violenta represión por parte de las alas castrenses más conservadoras y recicladas de la guerra - y con una nutrida ayuda de los Freikorps-, "rematando hasta a los heridos, (...) disparando con alegría a esas encarnaciones de la ignominia" (Gossweilier, 1982, p. 57; tomado de Kühnl, 199I, p. 29), se eliminaron poco a poco los focos que la revolución había dejado en toda Alemania. Sin embargo, pese a la parcial victoria del conservadurismo, las clases dominantes sabían que la coyuntura en la que se encontraban determinaba que la adopción de ciertas políticas en favor de las clases desfavorecidas era necesaria para mantener los fundamentos de su poder.

Las elecciones fueron organizadas para el I9 de enero de 1919, el partido SPD consiguió 165 representantes (el 39\% de la Asamblea); Zentrum, 90 (2I\%); y Demócratas o DDP, 75 (I8\%), de un total de 423 miembros (Bühler, I93I, p. 32), por lo que una necesaria coalición combinó sectores del Partido Centro Católico o Zentrum y del liberal Partido Demócrata Alemán o DDP con el partido SPD, consolidando un control del $78 \%$ de las curules. El 6 de febrero, la ciudad de Weimar fue epicentro del inicio de las discusiones que crearían la Constitución publicada finalmente el II de agosto del mismo año. 


\section{La Asamblea Nacional Constituyente}

La ciudad de Weimar fue entonces la opción escogida para reunir a los elegidos que debían escribir un texto constitucional. Una constitución que sería el pacto entre las distintas agrupaciones políticas que veían en la nueva república, una opción de salida de la peligrosa coyuntura en la que se encontraban, por lo cual apelaron al pueblo alemán para subsanar la feroz agitación. Sin embargo, el dilema radicó en cómo construir una constitución que representara las intenciones de sectores tan diferentes de la sociedad alemana ¿Cuál tendría que ser el articulado que demostrara una ruptura con el Antiguo Régimen, pero que al mismo tiempo diera cabida a las clases conservadoras, históricamente detentadoras del poder? Para analizar dichas preguntas es necesario ir al texto primario del Estado alemán: la Constitución de Weimar.

El preámbulo de las constituciones es un párrafo donde se plasman las ideas primarias que guían el resto de una carta magna. Para el reconocido jurista alemán Carl Schmitt, "el preámbulo debe indicar el espíritu de la obra constitucional" (Schmitt, 1927, p. 29). Por lo tanto, su análisis muestra los ideales y las esencias que quiere defender un pueblo o quien haga sus veces. Es en esta medida que la Constitución germana de 1919 enuncia que:

"La nación alemana, acorde en sus diversas ramas y animada de la voluntad de renovar y consolidar su Reich [Imperio] en nombre de la libertad y la justicia, servir a la paz interior y exterior y fomentar el progreso social, se ha dado esta Constitución." ${ }^{4}$

Este preámbulo menciona a un pueblo alemán consolidado en forma de nación, que reconocía sus "diversas ramas", propuesta que intentaba superar la histórica división étnica que representaba la fragmentación de Alemania en entidades regionales en un estilo de Estado federado de prusianos, bávaros, y sajones, entre otros, y pasaba a ser un Estado de alemanes. Fue aquí donde la unidad se manifestó, incluyendo en ella el reconocimiento de la diversidad que agrupaba lo germano. Además, la mención siguiente hace una referencia directa a la prolongación de lo que representaba el pasado Reich alemán, la "voluntad de renovar y consolidar" demostraban perse que la nueva Constitución estaría atada a algunas tradiciones venidas del Antiguo Régimen. Por lo tanto, es importante entender el texto de Weimar como un intento por reformar al Estado desde adentro, refrescando, tal vez, el aparataje institucional que sería imposible de sostener sin una profunda modernización y sin darle características que mostraran el enrolamiento del pueblo y de los nue-

4 Constitución del Imperio alemán del II de
agosto de I9I9, pág. 39. 


\section{Juan David Restrepo Zapata}

La Constitución alemana de Weimar (1919) ¿una utopía en medio de la crisis? Un análisis histórico a sus aspectos interventores, modernizadores y derechos sociales

vos actores que buscaban consolidar sus objetivos. Para Schmitt, apelar a un poder constituyente para realizar las transformaciones correspondientes, dotaba a la nueva Constitución de una validez y de una legitimidad imposible de superar con otros medios. Invocar a un poder primario dotaba al nuevo ordenamiento de una "fuerza y autoridad" capaz de adoptar un modo y una forma de existencia política (Schmitt, 1927, p. 86). Sin embargo, para Schmitt, es el mismo pueblo alemán, a través de sus representantes, el que reclama una renovación de su Reich, y no la fundación de uno nuevo: "Precisamente por ser una Constitución democrática, no funda la nueva un nuevo Estado alemán. Significa solo que un pueblo que creía hasta ahora no poder existir políticamente sino a base del principio monárquico, cuando desaparece políticamente ese principio, continuó su existencia por virtud de propia decisión política, mediante una Constitución que se da a sí mismo" (Schmitt, 1927, p. II3). En consecuencia, el Estado se mantiene, pero reorganizando o, en algunos casos, reformando 5 su Constitución. Una reforma bajo la legalidad y el orden existente. Conjuntamente, la conservación de la denominación como Reich - palabra que proviene del latín Imperium - puede evidenciar la intención de vincular "un sentido

5 Schmitt expone el caso de $\mathrm{H}$. Preuss, quien "habla incluso solo de simple reforma constitucional, [o el caso de] K. Beyerle: continuamos el viejo Reich”. (Schmitt, 1927, p. II3). monárquico" a la Constitución (Bühler, I93I, p. 38). Es por todo lo anterior que se desdibuja la idea de una profunda revolución en Alemania. Más bien se podría hablar de un reajuste o profunda reforma institucional.

La combinación que se expresó en esta Constitución podría representar una cohabitación de formas de gobierno que rescatan las particularidades de la monarquía, la aristocracia y la democracia. Al respecto, Norberto Bobbio ha planteado en su libro Estado, Gobierno y Sociedad (1985), que la posibilidad de la existencia de un gobierno mixto, tuvo sus orígenes en Platón y que esta fue rescatada durante la transformación constitucional ocurrida después de la Primera Guerra Mundial'. Bobbio cita a Schmitt, quien sostiene que "las constituciones del moderno Estado de derecho burgués son mixtas, porque en ellas están siempre unidos y mezclados diversos principios y elementos y, en cuanto tales, confirman una antigua tradición, según la cual el ordenamiento público ideal descansa en una unión y mezcla de los diversos principios políticos" (Bobbio, 1989 , p.I57). Esto, en parte, explicaría la condición de la Constitución de Weimar: "no había de ser individualista-burgués, ni socialista-bolchevista" (Schmitt, I927, p. 87). Además, el análisis que realiza Bobbio de diferentes teóricos, expone

6 Según Bobbio, dicho momento fue "uno de los períodos de mayor transformación constitucional que la historia haya conocido" (Bobbio, 1989, p.157). 
que en muchas ocasiones es la conjunción de modelos la que ha logrado una mayor estabilidad estatal a lo largo de la historia.

Entendiendo que este trabajo solo analiza los aspectos interventores, modernizadores y de derechos sociales de la Constitución de Weimar, se seguirá dicho orden. Cabe aclarar que la riqueza de dicha carta magna supera los parámetros de análisis aquí expuestos, ya que muchas temáticas por ella abordadas van más allá de los objetivos de esta investigación.

\section{INTERVENCIONISMO ESTATAL}

El intervencionismo de Estado rompía con gran parte de las tradiciones clásicas del liberalismo decimonónico dominado por el laissez faire, laissez passer. Los Estados fuertes comenzaron a aparecer desde las teorías mercantilistas del siglo xviII y se extendieron, en alguna medida, por la Europa industrializada del siglo xIx, donde un ejemplo de ello fue la política de protección obrera y económica, adoptada por Otto von Bismark. Por aspectos teóricos tomados del keynesianismo, muchos autores plantean que allí se encuentran los gérmenes del Estado de Bienestar que tuvo su furor en los años siguientes a la Segunda Guerra Mundial (Hobsbawm, 2009, p. 103). Un acercamiento básico al concepto nos indicaría que el intervencionismo estatal es la disposición a incentivar la participación de las entidades del Estado en la economía, "ya para asumir la gestión directa de determinadas áreas de la producción; ya para alentar o desalentar ciertas actividades según su conveniencia social; ya para restituir la libre competencia cuando esta se ha perdido por la acción monopolista; ya para utilizar el sistema tributario y la seguridad social como instrumentos de distribución del ingreso; ya para cortar abusos del poder económico privado o para orientar la economía de un país en determinada dirección" (Borja, 2017). Para Bobbio, un Estado fuerte o intervencionista, es aquel que otorga un derecho especial a las instituciones estatales de "regular la producción de bienes o la distribución de la riqueza, promueve ciertas actividades y desalienta otras, imprime una dirección al conjunto de la actividad económica del país" (Bobbio, 1989, p.I73). Usualmente, los partidos socialdemócratas han apoyado este tipo de Estado social, que de forma más tenue que la propuesta socialista, intenta regular la distribución de la riqueza, más no los medios de producción (Bobbio, 1989, p. 175).

Tomando las apreciaciones del sociólogo Anthony D. Smith, el Estado interventor o "científico" es un "poderoso disolvente del orden tradicional, en particular en un contexto poliétnico. Se trata de una etapa intermedia, inestable pero dinámica, entre el antiguo 
y el nuevo orden" (Smith, I97I, p. 375), en dicho orden cabría la adopción de medidas en sectores como "la guerra, la administración, la fiscalidad, las comunicaciones, el comercio, la educación, la seguridad de las personas y los bienes, la ley y la moral, e incluso el gusto estético y las modas" (Smith, I97I, p. 38I).

La Constitución alemana aborda una multiplicidad de disposiciones que versan sobre el orden económico, educativo, social, familiar y religioso, entre otros. Sus artículos permitían la vinculación directa del Estado en la regulación y control por parte de este, en las materias e intereses de los temas mencionados. Esto rompía con algunos aspectos de la tradición estatista - como en los casos inglés o estadounidense-, que pretendía la no intromisión del poder institucional en diferentes esferas de la vida y dejar que la "mano invisible" fuera la encargada de conseguir el tan anhelado orden. Es de resaltar que el intervencionismo de Estado no fue nuevo para Alemania — ni lo era para el mundo-, solo que las nuevas regulaciones iban más allá de lo acostumbrado. Algunos artículos importantes de Weimar que trataban el tema fueron:

Artículo 6: El Reich tiene a su cargo la legislación exclusiva sobre: (...) 6. Régimen aduanero, así como unidad del territorio aduanero y mercantil, y libre circulación de mercancías; 7. Organización de correos y telégrafos, inclu- yendo, además, los teléfonos (...)

Artículo 7. El Reich legisla sobre: (...) 7. Política demográfica, protección a la maternidad, a los lactantes, a la infancia y a la juventud; régimen sanitario, régimen veterinario y protección de las plantas contra enfermedades y agentes nocivos; (...) 9. Derecho obrero, seguro y protección de obreros y empleados, así como bolsas de trabajo; (...) I2. Derecho de expropiación; I3. Socialización de las riquezas naturales y empresas económicas, así como producción, elaboración, reparto y fijación de precios de bienes económicos para la economía colectiva; I4. Comercio, sistema de pesas y medidas, emisión de papel moneda, régimen bancario y bolsas; 15 . Tráfico de víveres y artículos de degustación, así como objetos propios de uso cotidiano; I6. Industria y minería; I7. Régimen de seguros; I8. Navegación, pesca de altura y pesca costera; 19. Ferrocarriles, navegación interior, circulación automotora por tierra, mar y aire; así como la construcción de carreteras, tratándose de tráfico general o en cuanto afecte la defensa del país; 20. Teatros y cines.

Un análisis global de los artículos anteriores pone de relieve varias cosas: primero, el fortalecimiento del mercado nacional obligaba, en algunos casos, a proteger mediante una carga arance- 
laria a los productos interiores, su regulación corría por cuenta del Estado, el cual —bajo su única discreción-, tenía la potestad constitucional de incrementarlos o rebajarlos, dependiendo de las necesidades que se estuviesen presentando (Artículo 6). Esta necesidad de fomentar el desarrollo nacional se daba en un momento de extrema debilidad económica. La Guerra desgastó el complejo industrial construido durante el Imperio y la capacidad fiscal del Estado estaba en entredicho. Segundo, la adopción de un ordenamiento que pudiera versar sobre la demografía del país, y con ello sobre los recién nacidos, los niños y los jóvenes, es una gran muestra del intervencionismo estatal en la vida cotidiana de la sociedad alemana. La Constitución abría la puerta a los legisladores para ir más allá y regular aspectos como la maternidad, derechos de la juventud, lo sanitario, lo veterinario e inclusive "la protección de las plantas contra enfermedades y agentes nocivos" (Artículo 7), de esta manera, el carácter interventor del Reich demostraba que estaba siendo planteado de una manera integral, que no solo tuviera en cuenta la economía, sino que también entrarían en el dominio estatal aspectos como la construcción de obras, la regulación del comercio, la industria y hasta la cultura. Además, en su Artículo 9, se aludía a la ampliación de la jurisdicción del Reich, siempre que esta tuviera la intención de conseguir el "bienestar común".
Los medios de transporte también fueron objeto de una exhaustiva intervención. Los ferrocarriles serían propiedad del Estado, quien se encargaría de su expansión y conservación en base del interés general. Además, aquellos que no estuvieran bajo su dominio, quedaban sujetos a la inspección de las autoridades correspondientes. Asimismo, todos los sistemas férreos quedaban a disposición del Estado por casos de defensa nacional ${ }^{7}$. También, las vías fluviales serían objeto de intervención y control por parte de la institucionalidad. El Artículo 97 expresaba que:

"Es deber del Reich asumir la propiedad y administración de aquellas vías navegables que sirvan para el tráfico general. (...) Con el traspaso de una vía navegable al Reich, adquiere este el derecho de expropiación, de imponer tarifas así como el régimen de aprovechamientos fluviales y de navegación"8.

Con todo lo anterior se configuraba un monopolio estatal a los medios de transporte, llevando la intervención a los niveles de posesión, dominio, control y operación de las arterias del Reich.

En cuanto a la vida social, el Estado se asignaba como misión "velar por la

7 Constitución del Imperio alemán, I919. Artículos 89, 90, 91, 94, 95.

8 Constitución del Imperio alemán, 1919. Art. 97. 


\section{Juan David Restrepo Zapata}

La Constitución alemana de Weimar (1919) ¿una utopía en medio de la crisis? Un análisis histórico a sus aspectos interventores, modernizadores y derechos sociales

conservación de la pureza, sanidad y fomento social de la familia", caso que frente a una libre interpretación, podría justificar algunas teorías vitalistas, nacionalistas o incluso puristas de la raza alemana. También otorgaba a la educación "de la prole", el carácter de "deber y derecho natural de los padres"10, y se definió que la educación de la juventud se debía atender por medio de instituciones públicas, donde la "formación de maestros deberá regularse homogéneamente, siguiendo principios que se aplican a la alta cultura en general". Además, el Estado podía inspeccionar las organizaciones escolares cuando así lo dispusiera ${ }^{11}$. Todo ello implicaba una agrupación de funciones, que pasarían por la autoridad y orden del Estado, que procuraría el "fomento social" y el "bienestar" de Alemania. Intervenir en aspectos como la familia y la educación expandía las posibilidades del Estado de llegar a todos los niveles de la sociedad. Con ello se aseguraría el control y la regulación desde lo micro hasta lo macro. Interpretando a Bobbio, se creó un Estado fuerte que intentaría menguar las luchas de poder, disminuir los riesgos y apaciguar las incertidumbres.

Un aspecto importante de tratar en este apartado es la reforma de la tierra

9 Constitución del Imperio alemán, 1919. Art. II9.

10 Constitución del Imperio alemán, 1919. Art. I2O.

11 Constitución del Imperio alemán, 1919. Art. I43, I44. que se consagra en la Constitución. El Artículo 155 habla sobre los usos y posesiones de la tierra, expresando que "el reparto y el aprovechamiento del suelo será inspeccionado por el Reich, de tal suerte que impida los abusos y tienda al objetivo de que cada alemán tenga una habitación sana y que todas las familias alemanas, especialmente las numerosas, tengan a su disposición una cantidad de terreno suficiente a sus necesidades”. También agregaba que "podrá ser expropiada la propiedad de aquellos inmuebles cuya adquisición se requiera para las necesidades de habitación, para el fomento de la colonización o rotulación, y para el mejoramiento de la agricultura”. Además, exponía que "el cultivo y explotación del suelo es un deber del propietario para con la colectividad. El aumento del valor del suelo, que no sea debido a una inversión de trabajo o de capital, redundará en beneficio de la colectividad”. Esta intervención del Estado rompía con la inviolabilidad del régimen de propiedad privada que, a pesar de consagrarse en la Constitución, tenía unos condicionantes claros, basados en la productividad.

La enorme tasa demográfica que presentaba Alemania en I9I9, aproximadamente 6I millones de habitantes, requería la desamortización de tierras sin uso. Esto exigió la adopción de herramientas fuertes por parte del Estado, que permitieran la enajenación de la propiedad privada con la función de colectivizarla y volverla productiva. Además, convirtió en deber el cultivo 
y la producción, como también refundó a la propiedad dentro del espíritu colectivo. Esta faceta de la Constitución destronaba a los latifundistas que se anclaban a la posesión de la tierra como sustento de su poderío económico. La colectivización de la tierra, al ser planteada como objeto para el bienestar de las familias, inauguraba una posición socializante de la propiedad, que invitaría a la expropiación, con lo cual tendría matices marxistas, pero que, al mismo tiempo, reconocía a la propiedad privada dentro del marco normativo. Por todo lo ante- riormente expuesto, Schmitt considera que "contradictorio y oscuro es el texto de la Constitución de Weimar respecto de la propiedad privada" (Schmitt, I927, p. 199), exponiendo la falta de garantías institucionales para afrontar los retos que allí se planteaban los legisladores.

La nueva Carta Magna reforzó los tentáculos del Estado, donde, además de su carácter nacionalista, se abarcaba una amalgama de funciones y de controles que permitiera conseguir el orden y la estabilidad en una sociedad revuelta e influenciada por ideologías de todos los colores.

\section{Modernización}

Este trabajo entiende la modernización como "el proceso de mutación del orden social, inducido por las transformaciones derivadas del desarrollo de la ciencia y la técnica" (Corredor, I992, p. 5I), donde se da un cambio también en el orden político y, en ocasiones, estructural. La modernización se convierte en el objetivo de los procesos transformadores y progresistas que plantean reformar la tradición en cuanto a las instituciones, el poder, las relaciones y acciones políticas y democráticas, los vínculos Iglesia-Estado, entre otros.

Siguiendo el análisis que realiza Consuelo Corredor en su texto "La modernización y la modernidad como procesos", se plantean básicamente dos tipos de modernización: la primera es aquella que se realiza desde la base, desde abajo - el pueblo-, y que obligatoriamente debe ser democrática, y desde la cual se construyó la mayoría de las sociedades que tienen en la actualidad un estadio "desarrollado", que ella misma elogia, y la denomina "modernización aventurera". Una segunda etapa en la modernización es aquella que se da desde arriba, desde la élite, donde ella es la que controla la modernización, sin espacio para la participación de la base social, implementándose obligatoriamente, y conservadora de los modelos tradicionales, la cual denomina "modernización rutinaria”, que posee como principal conductor a la burguesía.

Aplicando dicho análisis al caso alemán, se podrían contemplar los siguientes aspectos de la Constitución de Weimar. En primer lugar, la estructura 
del Estado se modificó de tal manera que se hiciera taxativa la separación y control de los poderes. La nueva Constitución enunciaba al Poder Legislativo, el Reichstag, como órgano de representación principal del pueblo alemán. Sus diputados "son representantes de todo el pueblo" y "solo están sometidos a su conciencia y no se hallan sujetos a ningún mandato"12. El Reichstag sería elegido por votación "universal, igual, directa y secreta, por todos los hombres y mujeres mayores de veinte años y de acuerdo con los principios de la representación proporcional"13. Con esto, se intentaba darle al Estado una característica parlamentaria -sin llegar a serlo-, que repartiría la representación y el carácter federativo en dos cámaras, el Reichstag y el Landtag, respectivamente. La primera, caracterizada por garantizar la centralida; mientras que la segunda garantizaba las "singularidades" (Schmitt, 1927, p.342) de cada país. Según Schmitt, este sistema bicameral acentuaba las diferencias, lo que vulneraba la "homogeneidad democrática" (Schmitt, 1927, p. 342). Es de resaltar que esta modernización de la estructura del Estado puso por encima de los demás poderes al Reichstag, por lo que aparentaría una efectiva representación del pueblo en las esferas de poder. Este órgano legislativo tendría una función de control frente

12 Constitución del Imperio alemán, 1919. Art. 2I.

13 Constitución del Imperio alemán, 1919. Art. 22. al gobierno y, a su vez, el Presidente del Reich tenía las competencias para disolverlo. La disolución se resolvería llamando a elecciones dentro de los siguientes sesenta días, y así, sería el pueblo el encargado de "resolver los conflictos entre los poderes" (Schmitt, I927, p. 4I3).

Otro aspecto modernizador era la creación de la figura de Presidente del Reich, que por medio del voto popular, directo y universal de todos los alemanes, representaría la unidad del pueblo y tendría las facultades de firmar tratados y alianzas internacionalmente, poseería el "mando supremo de todas las fuerzas militares"14, tendría las capacidades de declarar el Estado de excepción "suspendiendo provisionalmente, en todo o en parte, los derechos fundamentales" ${ }^{15}$ y del derecho de gracia, por lo cual, a pesar de sus pocas atribuciones, sería fundamental para el correcto desempeño del Reich. El Gobierno sería asumido por un gabinete ministerial presidido por un Canciller imperial, que sería nombrado por el Presidente, en dicho órgano descansaría el Poder Ejecutivo del Estado y tendría que tener la "confianza del Reichstag para ejercer su cargo"16. Este cambio de sistemas políticos en Alemania sería una mezcla

14 Constitución del Imperio alemán, 1919. Art. 47.

15 Constitución del Imperio alemán, 1919. Art. 48.

16 Constitución del Imperio alemán, 1919. Art. 54 . 
híbrida, con características y prácticas de algunos regímenes como el parlamentario, el presidencial o el semipresidencial, una especie de modernización del aparato estatal para buscar la eficacia burocrática.

En segundo lugar, la ampliación de derechos políticos y la homogenización de la igualdad ante la ley de hombres y mujeres, se consiguió con una serie de artículos que planteaban:

"Artículo ro9: Todos los alemanes son iguales ante la ley. Hombres y mujeres tienen por principio los mismos derechos y deberes políticos. Los privilegios o restricciones que en materia de derecho público se derivan del nacimiento o pertenencia a una clase determinada quedan abolidos. Los títulos nobiliarios servirán solo como parte del nombre y no se concederán en lo sucesivo. Solo podrán concederse títulos cuando designen un cargo o una profesión. Esto no afecta a los grados académicos. ${ }^{17}$

La adopción de la igualdad ante la ley de todos los alemanes - hombres y mujeres-, implicaba realizar la inclusión del sector femenino en el mundo político, en las mismas condiciones que lo realizaban los hombres. La nueva disposición constitucional reconocía, de este modo, que el papel de las mujeres sería fundamental para

17 Constitución del Imperio alemán, 1919. Art. I09. la República que planteaban en Weimar. Además, el contexto de Alemania demandaba una democratización de la sociedad y el pasado reciente del país, que posicionó a las mujeres en el sector industrial y económico, mientras los hombres luchaban en el frente de batalla. Ello obligó a los legisladores a extender los derechos y, con ello, los deberes. El caso femenino también fue tratado y complementado por el Artículo I28, donde se menciona que "todos los ciudadanos, sin distinción, son admisibles a los cargos públicos según su capacidad y aptitudes y con arreglo a las leyes". Y donde, además, "se derogan todas las disposiciones de excepción relativas a los funcionarios femeninos". De esta manera, las mujeres podían elegir y ser elegidas, en el marco que las leyes dispusieran. Continuando con el Artículo ro9, este eliminaba los históricos privilegios estamentales de una sociedad profundamente aristocrática, quebrando de esta manera las tradiciones de origen feudal y dando vía libre al nuevo mundo económico y político que deseaban los sectores socialdemócratas. La no distinción por clases fue una utopía de algunos legisladores progresistas. Sin embargo, en una sociedad acostumbrada a la tradición aristocrática y monárquica, la posterior aparición de Hindenburg en la presidencia del Estado daría una clara muestra del poco deseo de abandonar las arcaicas distinciones de poder en Alemania.

La modernización implicaba una 
clara política laica en el Estado. En sintonía con esto, la Constitución consolidaba el respeto por la diversidad religiosa en Alemania. El artículo 135 hablaba de la "plena libertad de creencia y de conciencia. El libre ejercicio del culto está garantizado por la Constitución y queda bajo la protección del Estado", libertad que era complementaria a las consagradas en los artículos II8, I23 y 24 de palabra, prensa, reunión y asociación. También el aparato estatal sería independiente de las formulaciones religiosas, y las creencias no podrían interferir en las funciones y decisiones de los empleados públicos ${ }^{18}$. La más explícita referencia al carácter no confesional de Alemania lo daría el Artículo 137, que señalaba que "no existe religión del Estado", con lo cual se rompía de lleno el vínculo que las iglesias habían tenido en los asuntos seculares y las limitaba a ejercer sus creencias en el marco de la ley y en iguales condiciones jurídicas, unas y otras.

Todo lo anterior intentaba transformar un sistema político basado en la jerarquización y en el mantenimiento de una sociedad estamental, que estaba desapareciendo en gran parte del mundo occidental. El proceso modernizador planteaba la construcción de nuevos valores en la vida política y social germana, donde coexistían experiencias de muchas índoles, especialmente las que buscaban un reajuste del modelo tradicionalista y otros que esperaban la entrada en el mundo moderno.

\section{Derechos sociales}

La industrialización acelerada, heredera de la Revolución Industrial británica, fue la promotora de la expansión de un sector fundamental para el desarrollo económico: la clase obrera. Estos hombres, mujeres e incluso niños, eran la base para el funcionamiento de los complejos industriales que buscaban la consolidación de un sistema económico basado en la obtención de lucro. Durante todo el siglo xIx, Alemania consiguió fomentar todo su aparataje industrial, reforzando el mercado na-

18 Constitución del Imperio alemán, 1919. Art. I36. cional y promoviendo la ciencia y la tecnología. Además, la masiva migración de personas a las ciudades, despojó de campesinos al sector agropecuario, y se pasó de un Estado con un régimen agrario, fundado en tiempos feudales, a un Estado industrial, que buscaba mercados y lucro dentro y fuera del país - un capitalismo burgués-. Los obreros se convirtieron en uno de los eslabones más importantes de las cadenas de producción y su contribución al sector muchas veces no se veía retribuida en salarios o en calidad de vida. Las fuerzas sindicales y los par- 
tidos obreros comenzaron en su lucha por el reconocimiento político y de derechos, que les permitiera subsistir en una sociedad privada de derechos, por lo cual, las últimas décadas del siglo decimonónico se cargaron de disputas y reconocimientos por parte del Estado. Bismarck, como buen estadista, comprendió que debía reducir las presiones de la sociedad, concediendo un paquete de derechos laborales. Por ejemplo, incluyó la Ley del Seguro de Enfermedad, en I883, que permitiría una atención a la salud de los trabajadores y una serie de garantías en la vejez. Los derechos sociales se convirtieron en las garantías estatales que permitirían la consecución de una vida digna de sus habitantes. Una especie de Estado social o benefactor, que tutelaba a sus ciudadanos.

Alemania, frente a los reclamos provenientes de los diferentes sectores sociales, conformó en la Constitución de Weimar un articulado paternalista que velaba por aspectos laborales, sanitarios y pensionales, entre otros, que en ocasiones fueron novedosos en su formulación. Frente a los derechos básicos, se estipulaba desde el Artículo 7 que: "El Reich legisla sobre: (...) protección a la maternidad, a los lactantes, a la infancia y a la juventud; régimen sanitario; (...) 9. Derecho obrero, seguro y protección de obreros y empleados, así como bolsas de trabajo (...)". De esta manera, las atribuciones legales que se tomaran desde el poder estarían mediadas por lo estipulado en la Carta Magna. Es de recordar que la Constitución estuvo precedida por un movimiento revolucionario obrero, que por medio de consejos intentó adueñarse del poder político, y que como parte del acuerdo entre socialdemócratas y conservadores, se tendrían en cuenta los reclamos del proletariado. Más adelante, la Constitución señala que "las energías de trabajo están bajo la protección especial del Reich. El Reich creará un derecho obrero homogéneo"19. Además, "el trabajo intelectual, el derecho del autor, del inventor y del artista, gozan de la protección y asistencia del Reich. Por medio de convenciones internacionales se procurará dar validez y protección, incluso en el extranjero, a la ciencia, arte y técnica alemanes" ${ }^{20}$. Todo ello facilitaba la reclamación y estructuración de derechos sindicales, conseguidos por el peso que la clase obrera ejercía en el Estado alemán de este período. También el derecho al descaso fue señalado por el Artículo I39, expresando que "el domingo y los días reconocidos como festivos, son puestos bajo la protección de la ley como días de descanso y de consagración espiritual”. El receso laboral también fue protegido por la Constitución cuando se tratara de ejercer derechos políticos, como en el caso de las elecciones.

19 Constitución del Imperio alemán, 1919. Art. I57.

20 Constitución del Imperio alemán, 1919. Art. I58. 
"Quien se hallare en una relación de trabajo o servicio como obrero o como empleado, tiene el derecho de disponer de todo el tiempo libre necesario para ejercer sus derechos cívicos, e incluso, cuando con ello no perjudique en gran manera la marcha del trabajo, a ejercer los cargos públicos de carácter honoríficos que se le hubiesen confiado. La ley determinará hasta qué punto tiene derecho a retribución" ${ }^{\prime 2}$.

Esto, sin duda, garantizaba los ejercicios democráticos que fueran convocados por las organizaciones obreras, algo que tenía suma relación con las libertades de sindicalización que se consagraban en el Artículo 159 y que velaban por la "defensa y mejora de las condiciones de trabajo y producción" y que no distinguía profesión. "Todas las confabulaciones o medidas que intenten coartar o restringir esta libertad son contrarias a la ley". Ello daría pié a fortalecer las causas y los discursos que buscaran la defensa de lo obrero, ya no como un ideal por buscar, sino por consolidar y potenciar.

En cuanto a la legislación social, el Artículo I6r exponía que "para conservar la salud y la capacidad de trabajo, para la protección de la maternidad y para la previsión contra las consecuen- cias económicas de la vejez, debilidad y azares de la vida, creará el Reich un vasto sistema de seguros con la colaboración directa de los asegurados". Esto complementaría las leyes sociales que tenía Alemania, y condicionaba el aporte de los trabajadores. La salud de ellos garantizaba la prestación adecuada de sus servicios y disminuiría la improductividad de las personas.

Una de las disposiciones que pudo interpretarse dentro del espectro socialista, era la que versaba sobre los consejos del trabajo y de economía —algo similar a los consejos propuestos desde el marxismo-- En ellas se hablaba de la colaboración de los empleados, a igual nivel que los empresarios en "la regulación de las condiciones de salario y de trabajo, así como en el desarrollo económico total de las fuerzas productoras ${ }^{\text {"22 }}$. Estos consejos, aunque eran meramente consultivos, invitaban a la vinculación de las fuerzas en los asuntos económicos que afectaran a ambas partes, para tratar de proyectar resultados consensuados.

Todo ello estructuró un Estado paternalista, de corriente social, que intentaba promulgar una legislación en favor de algunos sectores importantes para la economía, sin afectar los regímenes de propiedad o a los tenedores de los medios de producción.
21 Constitución del Imperio alemán, 1919. Art. I60.
22 Constitución del Imperio alemán, I9I9. Art. 165. 


\section{Conclusión}

El Estado alemán que refundó la socialdemocracia y sus grupos cercanos, junto con alguna parte de la facción conservadora, estaba construido sobre unas bases mixtas que dejaban entrever la necesidad coyuntural de poner orden a una sociedad inmersa en el caos, donde la amenaza de la revolución pasó de ser latente a real. Las acciones emprendidas erigían una estructura con aspectos liberales, pero de espíritu nacionalista, donde el tinte bolchevique se mezclaba con el espíritu capitalista. La República de Weimar fundaba un sistema político progresista, que poseía un cúmulo de compromisos sociales, de los cuales algunos autores se atreven a afirmar que sentaba las bases de un "Estado de Bienestar bastante avanzado", que estaba "sometido de forma constante a ataques procedentes tanto de la derecha como de la izquierda, debido al rechazo de un gran número de alemanes de la democracia como forma de gobierno (...)" (Fulbrook, 2009, p. 215). La Constitución fue, entonces, "una especie de acuerdo pacífico entre el capitalismo y el socialismo (...), pero que en términos de política real significaba, sin embargo, continuar reforzando el capitalismo" (Kühnl, 199I, p. 34).
Este encuentro entre posturas ideológicas mantuvo el statu quo de varios sectores de la sociedad alemana. Por un lado, los industriales y detentores del capital no sufrieron grandes transformaciones. Además, las jerarquías militares continuaron con su dominio tradicional. Por otro lado, la socialdemocracia y los sectores afines al progresismo, consiguieron establecer un sistema receptivo de las problemáticas de la gente común, que veía en la reconfiguración del Estado la posibilidad de solucionar sus inquietudes. La revolución se inició, pero nunca se consolidó. El espíritu del comunismo recorrió las calles de Alemania, pero nunca se materializó en un verdadero cuerpo de transformaciones, que inclinara al país por las ideologías triunfales en las tierras de los antiguos zares. El proletariado alemán decidió inclinarse por la estabilidad que le prometía la construcción de una Constitución escrita por sus representantes, y que nunca olvidó el espíritu del pueblo germano. Una Constitución que tradujo, sin premeditarlo, los ideales de un nacionalismo basado en la "superioridad" de un pueblo. 


\section{Juan David Restrepo Zapata}

La Constitución alemana de Weimar (1919) ¿una utopía en medio de la crisis? Un análisis histórico a sus aspectos interventores, modernizadores y derechos sociales

\section{BibLIOgRAFÍA}

Artola, M. (2005). Constitucionalismo en la Historia. Barcelona: Crítica.

Bobbio, N. (1989). Estado, gobierno y sociedad. México: Fondo de Cultura Económica.

Borja Cevallos, R. (2016). Enciclopedia de la Política. Recuperado de http://www. enciclopediadelapolitica.org/Default. aspx?i=e\&por $=$ c\&idind $=307 \&$ termino $=$ constitucion. Consultado el $22 \mathrm{de}$ mayo de 2016.

Bühler, O. (I93I). Formación de la nueva constitución del Reich. La Constitución alemana. Madrid: Editorial Labor.

Burke, P. (1993). Formas de hacer Historia. Madrid: Alianza Editorial.

Carr, E.H. (1963). Estudios sobre la revolución. Madrid: Alianza Editorial.

Carrillo, D. (2007). Una aproximación sobre la evolución teórica del Estado. Revista Cuestiones Políticas 38: I25-I42.

Casa Gonzales, M. (2010). Hitler y el Nazismo. Un análisis crítico en diálogo con las reflexiones del historiador británico Ian Kershaw: I-I3.

Collotti, E. (1972). La Alemania nazi: desde la República de Weimar hasta la caída del Reich hitleriano. Madrid: Alianza.

Constitución del Imperio (Reich) Alemán, del II de agosto de I9I9 (I930). Textos constitucionales españoles y extranjeros. Zaragoza: Athenaeum.

Corredor Martínez, C. (1992). La modernización y la modernidad como procesos. Los límites de la modernización. Bogotá, CINEP: Ediciones Antropos.

Fulbrook, M. (2009). Historia de Alemania. Madrid: Akal.
Gossweilier, K. (1982). Kapital, Reichswehr und NSDAP 1919-1924. Berlín.

Hernández, D. (2010). Idea del Estado en Carl Schmitt. Aportes para una genealogía de lo político. Revista Argumentos UAM 64: I07-I29.

Hobsbawm, E. (1999). Historia del siglo XX, I9I4-I99I. Buenos Aires: Critica.

Hobsbawm, E. (2009). La era del Imperio: I875-I9I4. Buenos Aires: Critica.

Jellinek, G. (2000). Teoría general del Estado. Granada.

Koselleck, R. (20I2). Historias de Conceptos. Estudios sobre semántica y pragmática del lenguaje político y social. Madrid: Trotta.

Kühnl, R. (199I). La República de Weimar: establecimiento, estructuras y destrucción de una democracia. Valencia: Alfons El Magnànim.

López Olivia, J. (2010). La Constitución de Weimar y los derechos sociales. Revista Prolegómenos I3, 26: 233-243.

Martin de la Guardia, R. (2005). Sobre una nueva visión de la República de Weimar. Memoria y civilización: 223-230.

Monroy, M. (2005). Concepto de Constitución. Anuario de derecho constitucional latinoamericano: $\mathbf{1 3}-42$.

Parker, R. (1987). El siglo xx, Europa 19181945. Madrid: Siglo XXI.

Pérez, R. (2000). Constitución, derecho y poder judicial en la República de Weimar (Alemania 1919-1933). Jueces para la democracia 32: 56-67.

Periódico ABC, Madrid, Io de noviembre de 1918.

Periódico ABC, Madrid, II de noviembre de 1918. 
Periódico ABC, Madrid, "Apuntes para la historia de la revolución alemana”, 5 de febrero de I9I9.

Portantiero, J. (1982). Los escritos políticos de Max Weber: la política como lucha contra el desencantamiento. Desarrollo Económico 22, 87: 43I-436.

Restrepo Zapata, J. (2015). El Estado alemán durante la República de Weimar. Tempus Revista en Historia General I: IO4-II7.

Sánchez Ron, J. (1999). Científicos en la república de Weimar. Occidente 2I2.

Sánchez, G. (2006). Intelectuales, política y sociedad: objeto, método y posibilidades de una reflexión necesaria en las ciencias sociales. Revista Sociedady Economía Io: 225-228.

Schmitt, C. (1927). Teoría de la Constitución. Madrid: Revista de Derecho privado. Schmitt, C. (2006). El concepto de lo político. Madrid: Alianza.

Smith, A. D. (197I). La legitimación dualista: matriz del nacionalismo étnico. Teorías del nacionalismo. Barcelona: Labor. Treue, W. (1968). Alemania desde 1848, ojeada histórica. Bremen: Inter Nationes.

Von Baden, M. (1927). Erinnerungen und Dokumente. Berlín.

Weiss, P. (1975). Ästhetik des Widerstands, vol. I. Frankfurt. 